\title{
SHIPBOARD DEPLOYMENT OF A VHF OSCR SYSTEM FOR MEASURING OFFSHORE CURRENTS
}

\author{
By Richard A. Skop and Nicholas J. Peters
}

$\mathrm{I}_{\mathrm{N}}$ $I_{N}$ JULY 1994, an OSCR unit was deployed aboard the R/V Columbus Iselin to explore the feasibility of obtaining offshore, vector surface currents from a single platform. The concept is straightforward. With the vessel stationary at some location. the OSCR transmit-receive cycle is initiated, and the measured radial currents over the OSCR grid are recorded. The ship then transits to a new location, the transmit-receive cycle is reinitiated, and the measured radial currents are again recorded. With the existing OSCR system, the OSCR grid moves along with the ship. Hence, to construct vector surface currents from the measured radial currents at the two ship locations, pairs of cells within reasonable proximity to each other are identified (in our case, post-experiment), the average position of the pair is calculated, and both radial currents are assumed to have their origins at this average position.

In practice, a ship cannot remain stationary at a fixed location. To maintain the constant heading necessary for beamforming, the Columbus Iselin was operated at a forward speed of $\sim 1 \mathrm{~m} \mathrm{~s}^{-1}$ during the 5-min OSCR transmit-receive cycle. The forward speed was determined from two or three successive, 2-min interval, Global Positioning System (GPS) readings during the transmit-receive cycle. The forward speed biases a measured radial current by adding to it the component of the forward speed in the direction of the radial. To correct for this bias and obtain the radial current that would be measured from a stationary site, the appropriate component of the forward speed must be subtracted from the measured radial current (Peters and Skop, 1997).

Additionally, wave-induced, periodic ship motions can degrade the spectral returns to the point where the Bragg peaks cannot be identified, as dis-

Richard A. Skop. Rosenstiel School of Marine and Atmospheric Science, University of Miami. Miami, FL 33149. USA. Nicholas J. Peters, Prince William Sound Science Center, Cordova. AK 99574. USA. cussed by Skop et al. (1994) and Peters and Skop (1997). The periodic motions were monitored continuously during a transmit-receive cycle using a six-channel accelerometer system (Skop et al., 1994). The motions were found to be negligible, and the spectral returns were unaffected, because of the light seas encountered during the experiment.

Finally, the transmit antenna and the receive antenna elements must be mounted aboard the vessel in a manner that minimizes ship hull and superstructure interference with the transmitted and backscattered signals. The mounting arrangement for the July 1994 deployment was identical to one used in an earlier deployment where the Columbus Iselin was four-point anchored and shared an OSCR grid with a land-based unit. The analysis of the ship and shore-based spectra from this earlier deployment demonstrated that the mounting arrangement used successfully averted ship hull and superstructure interference (Skop et al., 1994).

The July 1994 experiment was conducted with the ship-referenced OSCR grids overlapping in the high-speed, northerly flowing Florida Current. The vector surface currents extracted from the OSCR measurements agreed well with the expected values of the speed and direction of the Florida Current (Peters and Skop, 1997). These results establish the feasibility of measuring ocean surface

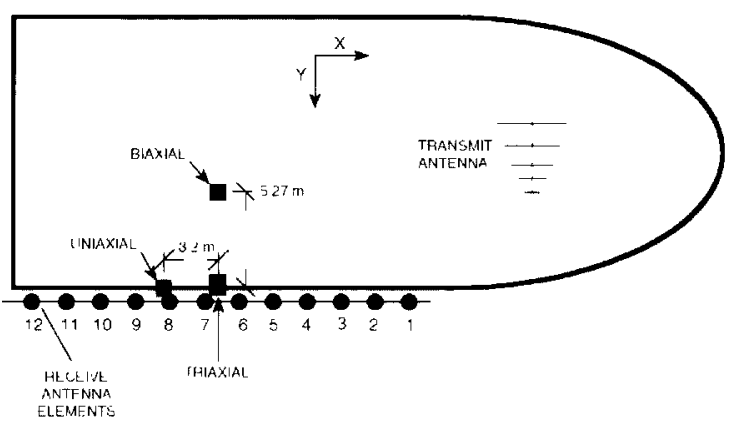

Fig. I: The OSCR and accelerometer system arrangements aboard the Columbis Iselin. Not to scale. 


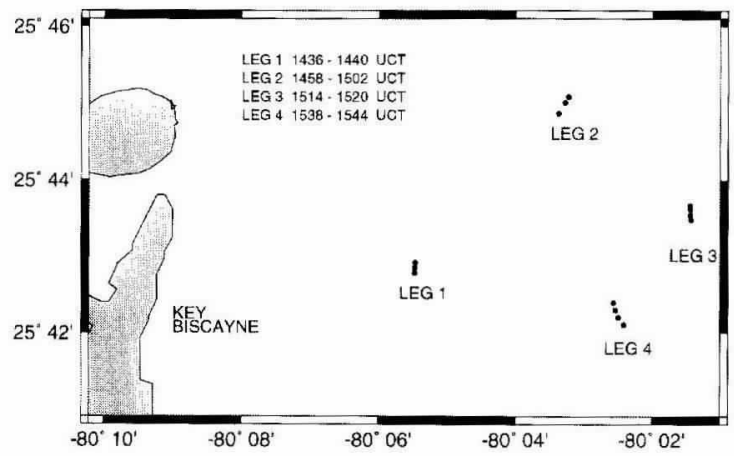

Fig. 2: Ship trajectories for the first diamond transect during the July 1994 offshore experiment.

currents from a single platform using an OSCRtype system.

\section{Conduct of the Experiment}

The OSCR installation aboard the Columbus Iselin is depicted in Figure 1. The unit was used in its very high frequency (VHF; $50 \mathrm{MHz}$ ) mode. The Yagi transmit antenna was located as far toward the bow as possible and positioned so that its main lobe did not intersect the ship superstructure. The antenna was also raised on pylons to prevent any intersection between its main lobe and the bulwarks. The receive antenna elements were mounted, whip ends vertically upward, slightly
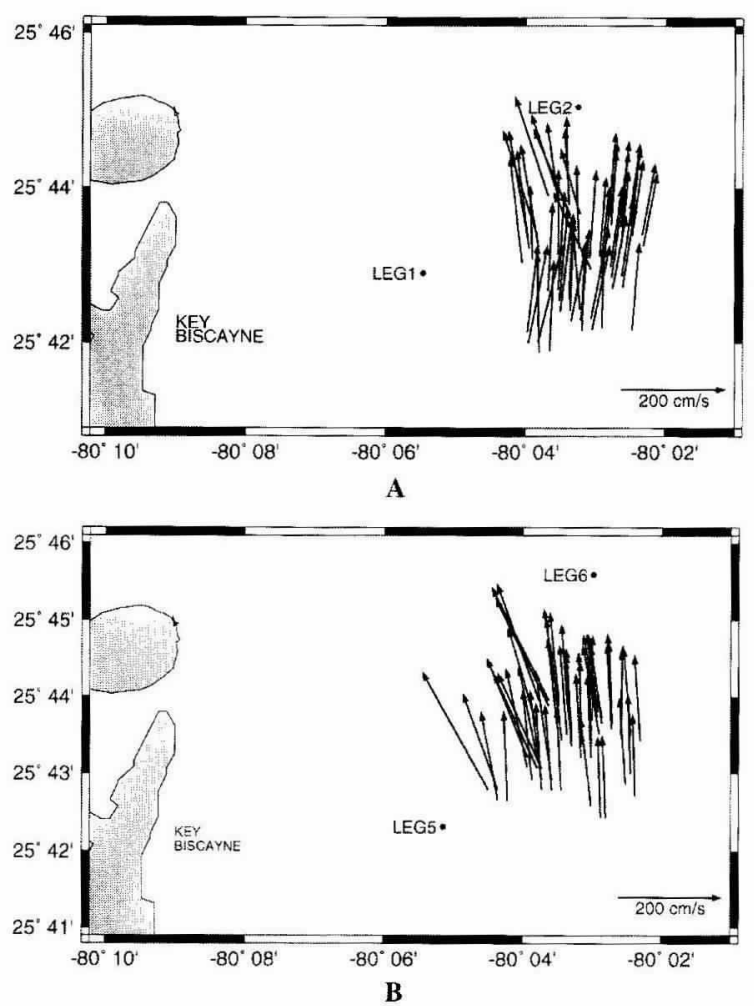

Fig. 3: Vector current maps of the Florida Current on July 22, 1994. (A) From legs 1 and 2 at 1500 UTC; $(\boldsymbol{B})$ from the corresponding legs of the second offshore transect at 1700 UTC. outboard of the hull and slightly above the bulwarks. Twelve receive antenna elements were used with a horizontal spacing of $3 \mathrm{~m}$ between elements. The transmit antenna and the receive elements were electrically insulated from direct contact with the ship and were commonly grounded to the ship electrical ground.

The ship made transects, twice, in a diamond pattern offshore of Key Biscayne and within the Florida Current. The transmit-receive cycles coincided with the ship at the corners of the diamond. The ship path and UTC times from immediately preceding to immediately following each data collection cycle are shown in Figure 2 for the first diamond transect. Each diamond transect was initiated with a south to north pass (leg 1), followed by a west to east pass (leg 2) and a north to south pass (leg 3), and concluded by an east to west pass (leg 4). The influence of the northerly flow of the Florida Current can be seen in Figure 2 through the northerly drift of the ship during the west to east and east to west passes.

\section{Vector Surface Currents}

The vector surface current maps constructed from legs 1 and 2 of the first offshore transect and from the corresponding legs of the second offshore transect are shown, respectively, in Figure 3, A and B. A northerly surface current on the order of $170 \mathrm{~cm} / \mathrm{s}$ was found from the data. For the vector current map constructed from legs 1 and 2 (Fig. $3 \mathrm{~A}$ ), the mean value of the current over the OSCR grid is $163 \mathrm{~cm} / \mathrm{s}$ with a standard deviation of 20 $\mathrm{cm} \mathrm{s}^{-1}$. The mean direction (bearing from north) of the flow is $1^{\circ}$ with a standard deviation of $10^{\circ}$. For the vector current map constructed from the corresponding legs of the second offshore transect (Fig. $3 \mathrm{~B}$ ), the mean value of the current over the OSCR grid is $177 \mathrm{~cm} \mathrm{~s}^{-1}$ with a standard deviation of 24 $\mathrm{cm} \mathrm{s}^{-1}$. The mean direction of the flow is $352^{\circ}$ with a standard deviation of $8^{\circ}$. The mean values of the current magnitude and direction are consistent with the values measured in the Florida Current by Leaman et al. (1987).

\section{Acknowledgments}

This work was supported by the U.S. Naval Research Laboratory (SSC) and the U.S. Office of Naval Research under grant N00014-93-1-G900 and by the U.S. Naval Research Laboratory (SSC) under grant N00014-95-1-G905.

\section{References}

Leaman, K.D., R.L. Molinari and P.S. Vertes, 1987: Structure and variability of the Florida Current at $27^{\circ} \mathrm{N}$ : April 1982-July 1984. J. Phys. Oceanogr., 17, 565-583.

Peters, N.J. and R.A. Skop, 1997: Measurements of ocean surface currents from a moving ship using VHF radar. $J$. Atmos. Oceanic Technol., 14(3), 676-694.

Skop, R.A., D.B. Ross, N.J. Peters and L. Chamberlain, 1994: Measurements of coastal currents using a ship-based VHF radar system. RSMAS Tech. Rep. 94-001, Rosenstiel School of Marine and Atmospheric Science, University of Miami, $25 \mathrm{pp} . \square$
The mean values of

the current magni-

tude and direction

are consistent with

the values measured

in the Florida

Current... 